Research Article

\title{
Flocculation Settling Characteristics of Ultra-Fine Iron Tailings with Rich Gypsum
}

\author{
Daiqiang Deng $\mathbb{D i D}^{1,2}$ and Guodong Cao $\mathbb{i D}^{1}$ \\ ${ }^{1}$ College of Civil Engineering and Mechanics, Xiangtan University, Xiangtan 411105, China \\ ${ }^{2}$ College of Mining Engineering, Guizhou Institute of Technology, Guiyang, Guizhou 550003, China \\ Correspondence should be addressed to Daiqiang Deng; ustbb20070025@126.com and Guodong Cao; gdcao@xtu.edu.cn
}

Received 22 February 2021; Revised 26 February 2021; Accepted 5 March 2021; Published 17 March 2021

Academic Editor: Lijie Guo

Copyright (c) 2021 Daiqiang Deng and Guodong Cao. This is an open access article distributed under the Creative Commons Attribution License, which permits unrestricted use, distribution, and reproduction in any medium, provided the original work is properly cited.

\begin{abstract}
Because of the uniqueness of geological mineralization, tailings obtained from Chenchao Iron Mine have low $\mathrm{SiO}_{2}$ content of only $27.80 \%$. Content of $\mathrm{Al}_{2} \mathrm{O}_{3}$ and $\mathrm{MgO}$ is $13.31 \%$ and $\mathrm{CaSO}_{4}$ is $22.09 \%$. The fineness modulus of the ores is large enough for convenient mineral separation, thus resulting in $16.03 \%-5 \mu \mathrm{m}$ particles and $27.76 \%-10 \mu \mathrm{m}$ particles in the tailings, respectively. The average particle size is only $69.36 \mu \mathrm{m}$; it belongs to the category of very fine tailings. The natural sedimentation of tailings is extremely slow due to the comprehensive effects of their physical and chemical properties. Hence, sedimentation tests using four types of flocculating agents are conducted to accelerate the sedimentation of the tailings of Chenchao Iron Mine. Compared with natural sedimentation, the flocculating sedimentation is considerably quicker. Among the four flocculants, the sedimentation of sample using the special BASF flocculant is the fastest. When the tailings of 1 ton add this flocculant of $20 \mathrm{~g}$, the maximum settling concentration reaches $60.98 \%$ after $40 \mathrm{~min}$ and its special gravity is $1.577 \mathrm{~g} / \mathrm{cm}^{3}$, thus it fulfills future requirements of filling technologies. As the largest iron mine in the mid-southern region of China, Chenchao Iron Mine must turn to filling mining. This study can provide technological support for goaf management and environment-friendly treatment of solid waste in the Yangtze River basin, which plays important roles in ecological protection.
\end{abstract}

\section{Introduction}

Properties of tailings and agents in mineral processing flow sheet are often studied with respect to mine filling. For example, some mines have ultra-fine tailings that are easy to suspend and sediment slowly under natural conditions, thus making the feeding concentration and flow rate difficult to control. Under these circumstances, flocculants should be added to tailings to accelerate sedimentation and reach a high settling concentration in a short time, thus realizing high-concentration filling, which is easy to control $[1,2]$. Notably, tailings in some mines have special properties. Except for the small particle size, the mineral composition of tailings is relatively complicated, thus making its sedimentation difficult and influencing the follow-up filling. Special treatment is needed to realize the desired concentration $[3,4]$.
Natural and flocculation settling experiments have been conducted for the sedimentation of ultra-fine tailings in numerous related studies. Through a contrast experiment of different flocculants and process control, the best flocculant and its application conditions have been determined [5-7]. Regarding flocculation settling experimental method and laws of tailings, Zhou and Zhang [8] conducted natural and flocculation settling experiments of tailings in a measuring cylinder and tested the settling concentration and bulk density of tailing slurry. Moreover, some studies analyzed the sedimentation process of tailings to determine the mechanical mechanism of tailing settling through flocculation settling experiments and provided references for actual application $[2,9,10]$. A sedimentation prediction model for tailings has been established through experimentation, thus providing references for similar studies [11]. Viewed from the microscopic molecular forces of inorganic 
and macromolecular flocculants, related studies have explored the flocculation kinetics of aluminum oxide and polyacrylic acid and disclosed the action mechanism of polyacrylate flocculation under different concentrations [12]. As an equipment of tailing concentration, deep-cone thickeners are being used increasingly often recently and have become the first choice in slurry preparation in filling design. Two studies conducted practical analyses of solid concentration distribution and concentration of pasty fluid in deep-cone thickeners, thus providing technological support to the use of high-efficiency thickeners [13, 14]. Other studies analyzed the action mode and application advantages of flocculants, thus providing a direction for the R\&D of flocculant products $[15,16]$.

For the concentration technology of extremely fine particle tailings which has been gradually developed in recent years, combined with the technical problems appearing in the field, new technologies, new equipment, and new materials have been applied to solve the difficult problems in the production. For example, in terms of the settlement and concentration of fine tailing, researchers calculated the size of the efficient thickener with the help of laboratory test results, and it played a good role in the concentration of copper tailing [17]. In terms of paste filling design and application, the relevant researchers summarized the past technological development and put forward views on the future technological trend, which provided a reference for the determination of fine tailings concentration and optimal discharge concentration. In the selection of tailings settlement concentration flocculant, the researchers added super flocculation in the flocculation and settlement process of ultra-fine tailings, optimized the settlement behavior by analyzing the particle size distribution of tailings, and finally achieved a good effect in the paste joint filling process [18-21].

Considering the high gypsum content and slow sedimentation of ultra-fine tailings in Chenchao Iron Mine, natural and flocculant sedimentation experiments of tailings were conducted in this study to provide references for the future mass flow filling system of the mine. As the largest iron mine reserve in the mid-southern region of China, Chenchao Iron Mine is rich in high-quality iron ore reserves. Underground mining will be performed comprehensively after the open pit of the mine is closed to utilize local resources reasonably and sustainably.

Filling mining is essential for the future. Therefore, flocculation settling experiments of tailings should be conducted as they can offer technological parameters for the future introduction of deep-cone thickeners into filling systems. This study not only plays an important role in goaf management and reutilization of solid wastes in the Yangtze River basin but can also protect the local ecological environment and promote harmonious development between mine production and natural ecology.

\section{Materials and Methods}

2.1. Tailings. The basic physical properties of the tailings are shown in Table 1 . The stacking porosity of the tailings in
Chenchao Iron Mine was $42.6 \%$, which was relatively high. The angle of repose, which is influenced by mineral composition, was $33.73^{\circ}$. Natural slope angle is very important for material transportation in filling engineering. In some other mining enterprises, the natural slope angle of tailings is usually $35 \sim 40^{\circ}$. The $\mathrm{CaSO}_{4}$ content of the tailings made them difficult to be stacked high. When stacked high manually, tailings can easily creep downward and scatter due to their small relative internal friction.

The particle size distribution of tailings is shown in Figure 1. It can be seen from Figure 1 that there are many fine particles, of which the content of $-5 \mu \mathrm{m}$ particles and $-20 \mu \mathrm{m}$ particles is $16.03 \%$ and $40.46 \%$, respectively. The average particle size is $69.36 \mu \mathrm{m}$. About $10 \%$ particles can pass through the sieve of $3.2 \mu \mathrm{m}$ pore, and $60 \%$ particles can pass through the sieve of $52 \mu \mathrm{m}$ pore. The high content of fine particles will have a certain negative effect on the settlement of tailings. The fine particles can be suspended in water for a long time, resulting in slow settlement of tailings. Meanwhile, tailings are mostly flaked, and there is a large force between them and water molecules in the settlement process, so the settlement is slow. For tailings of very fine particles, its gravity is very small, so the buoyancy is dominant. It hardly sinks. Moreover, the tiny particles may form colloidal solution; they will attract or repel each other due to electrostatic interaction, so the particles will do chaotic lateral movement in a horizontal direction. The time of particles suspending in the tail slurry will greatly increase which results in slow subsidence.

The chemical composition of the tailings is shown in Figure 2. The tailings had small $\mathrm{SiO}_{2}$ content of only $27.80 \%$. $\mathrm{Al}_{2} \mathrm{O}_{3}$ and $\mathrm{MgO}$ accounted for $13.31 \%$, and $\mathrm{CaSO}_{4}$ took up $22.09 \%$ of the tailings. The content of $\mathrm{SiO}_{2}$ in tailings is very important for the consolidation, hardening, and permeability of materials in filling engineering. In some other mining enterprises, the content of $\mathrm{SiO}_{2}$ in tailings is usually about $50-75 \%$. The natural sedimentation of tailings is relatively slow and high settling concentration and bulk density are difficult to reach in a short time due to the comprehensive effects of their special physical and chemical properties.

\subsection{Flocculants}

(1) Special BASF flocculant (model no. Pheomax9010) for tailing settling, Germany

(2) BASF anionic flocculant with high molecular weight (model no. $\mathrm{M}^{3} 42$ ), Germany

(3) Anionic flocculant with 12,000,000 MW, Northern Chemistry

(4) Nonionic flocculant with $12,000,000 \mathrm{MW}$, Northern Chemistry

2.3. Water. In the experiments, common tap water at room temperature and $\mathrm{pH}=7$ was used to prepare the tailing slurry and flocculant solution. 
TABle 1: Physical properties of tailings.

\begin{tabular}{lcccc}
\hline Material & Special gravity & Bulk density $\left(\mathrm{t} / \mathrm{m}^{3}\right)$ & Dense porosity $(\%)$ & Angle of repose $\left({ }^{\circ}\right)$ \\
\hline Tailings & 2.77 & 1.590 & 42.60 & 33.73 \\
\hline
\end{tabular}

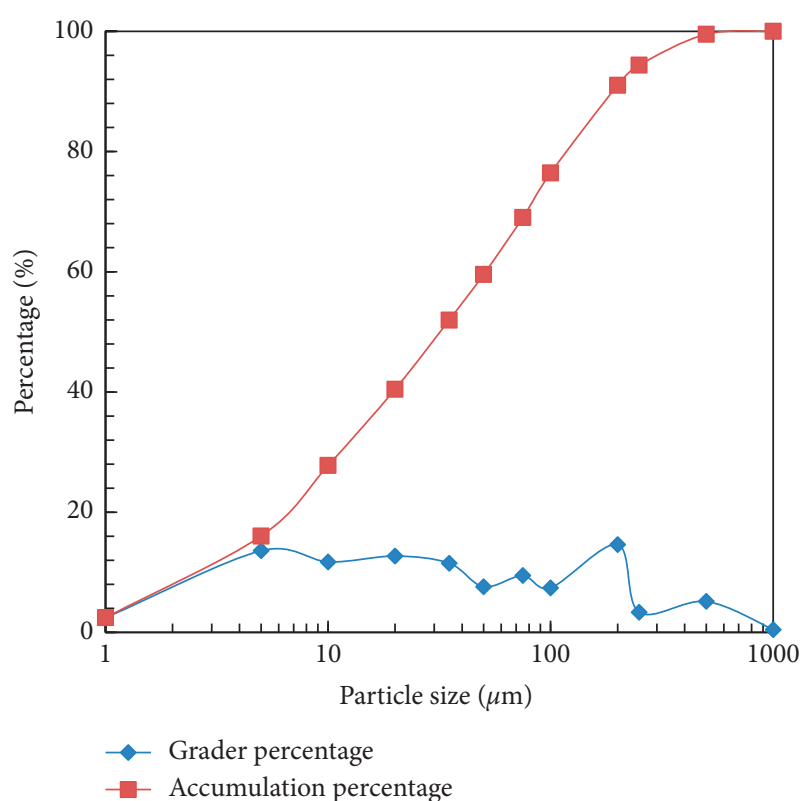

FIgure 1: Particle size distribution curve of tailings.

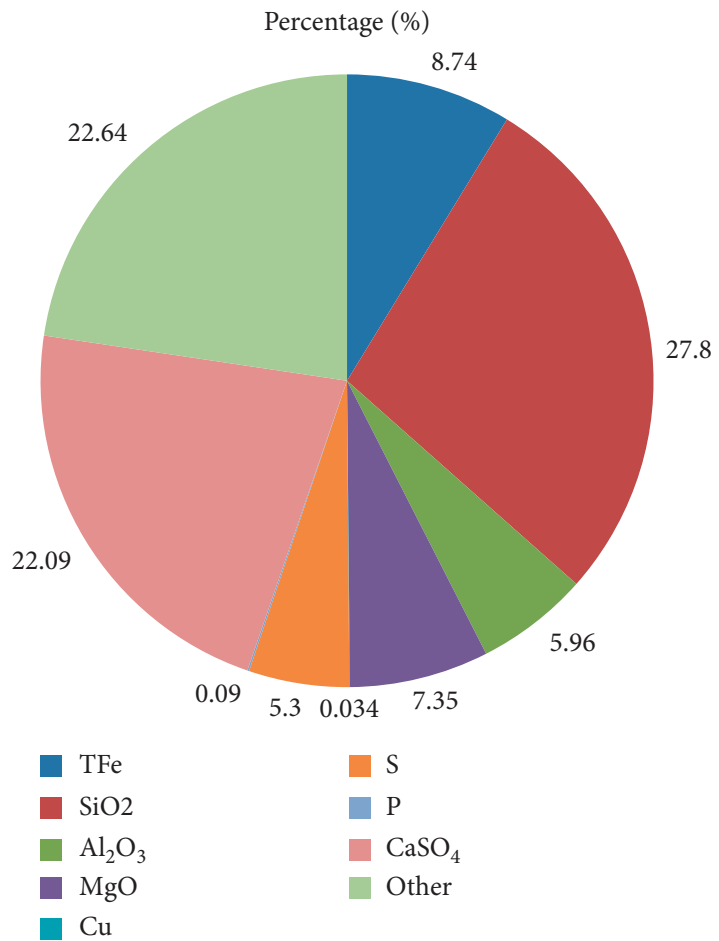

Figure 2: Chemical composition of tailings.

\subsection{Preparation of Tailing Slurry and Flocculant Solution.} The initial concentration of the tailing slurry was $40 \%$, and the concentration of the flocculant solution was $3 \%$. The flocculant dosage per ton of the dry tailings was $20 \mathrm{~g} / \mathrm{t}$ of the flocculants Pheomax9010 BASF and $\mathrm{M}^{3} 42$ BASF and $40 \mathrm{~g} / \mathrm{t}$ of the anionic flocculant with 12,000,000 MW (Northern Chemistry) and the nonionic flocculant with 12,000,000 MW (Northern Chemistry).

2.5. Flocculating Sedimentation Experiment. The particle size, shape, and chemical composition of tailings can influence the settling characteristics of tailing slurry considerably. These parameters determine the stacking state and settling concentration and bulk density of tailings. The tailings in Chenchao Iron Mine are difficult to sediment, except in natural sedimentation experiments. Thus, flocculating sedimentation experiments using four different flocculants were conducted in this study with the aim of recognizing the best flocculant for tailing settling. Changes in supernate volume in a $1000 \mathrm{ml}$ cylinder were recorded; according to the recorded data, the net water growth and variations in settling concentration and bulk density were calculated. The details of the experimental programs are listed in Table 2.

\section{Experimental Results}

3.1. Natural Sedimentation. The natural sedimentation experiment, which used no flocculants and tested the sedimentation process of tailings under natural conditions, was compared with flocculating sedimentation. The initial concentration of the tailing slurry was $40 \%$. Combined with the technological parameters in the future daily filling production process, the concentration of tailing mortar transported from the dressing plant to the filling slurry preparation station is about $40 \%$, so the preparation concentration of the tailing mortar of this group is $40 \%$.

The variations in the natural sedimentation test parameters of the tailings are shown in Figure 3. In the natural sedimentation experiment, the net water growth climbed up gradually before reaching the maximum of $200 \mathrm{ml}$ at $10 \mathrm{~min}$, declined during the 10-40 min interval, and remained the same after $50 \mathrm{~min}$. The water volume continuously increased rapidly within 0-30 $\mathrm{min}$, increased slowly in the 30-50 min interval, and remained the same after $120 \mathrm{~min}$. The slurry volume decreased rapidly within 0-28 min, decreased continuously at a low speed during the 28-120 min interval, and became stable after $120 \mathrm{~min}$. The total water and slurry volumes followed a linear development law throughout the entire experiment and did not show evident changes.

The variation curves of the settling concentration and bulk density of the tailings under natural conditions are shown in Figure 4. The settling bulk density increased rapidly in the first $30 \mathrm{~min}$, reached $1.484 \mathrm{t} / \mathrm{m}^{3}$, increased slowly from $1.600 \mathrm{t} / \mathrm{m}^{3}$ to $1.667 \mathrm{t} / \mathrm{m}^{3}$ during the $30-120 \mathrm{~min}$ interval, and remained the same after $120 \mathrm{~min}$. The settling concentration presented a similar variation law with the settling bulk density, increasing rapidly to $54.35 \%$ in the first 
TAвLE 2: Natural and flocculating sedimentation experiments of tailings.

\begin{tabular}{|c|c|c|c|c|c|}
\hline $\begin{array}{l}\text { Experiment } \\
\text { no. }\end{array}$ & Test type & Name of flocculants & $\begin{array}{c}\text { Concentration of } \\
\text { flocculant solution } \\
(\% \text { ) }\end{array}$ & $\begin{array}{c}\text { Flocculant dosage } \\
\text { per ton of dry tailing } \\
(\mathrm{g} / \mathrm{t})\end{array}$ & $\begin{array}{l}\text { Initial concentration } \\
\text { of tailing slurry (\%) }\end{array}$ \\
\hline$\# 1$ & $\begin{array}{c}\text { Natural } \\
\text { sedimentation }\end{array}$ & No flocculant & - & - & 40 \\
\hline$\# 2$ & $\begin{array}{c}\text { Flocculating } \\
\text { sedimentation }\end{array}$ & Pheomax9010 BASF & 3 & 20 & 40 \\
\hline$\# 3$ & $\begin{array}{c}\text { Flocculating } \\
\text { sedimentation }\end{array}$ & $\mathrm{M}^{3} 42$ BASF & 3 & 20 & 40 \\
\hline$\# 4$ & $\begin{array}{c}\text { Flocculating } \\
\text { sedimentation }\end{array}$ & $\begin{array}{c}\text { Anionic flocculant with } \\
\text { 12,000,000 MW (Northern } \\
\text { Chemistry) }\end{array}$ & 3 & 40 & 40 \\
\hline$\# 5$ & $\begin{array}{c}\text { Flocculating } \\
\text { sedimentation }\end{array}$ & $\begin{array}{l}\text { Nonionic flocculant with } \\
\text { 12,000,000 MW (Northern } \\
\text { Chemistry) }\end{array}$ & 3 & 40 & 40 \\
\hline
\end{tabular}

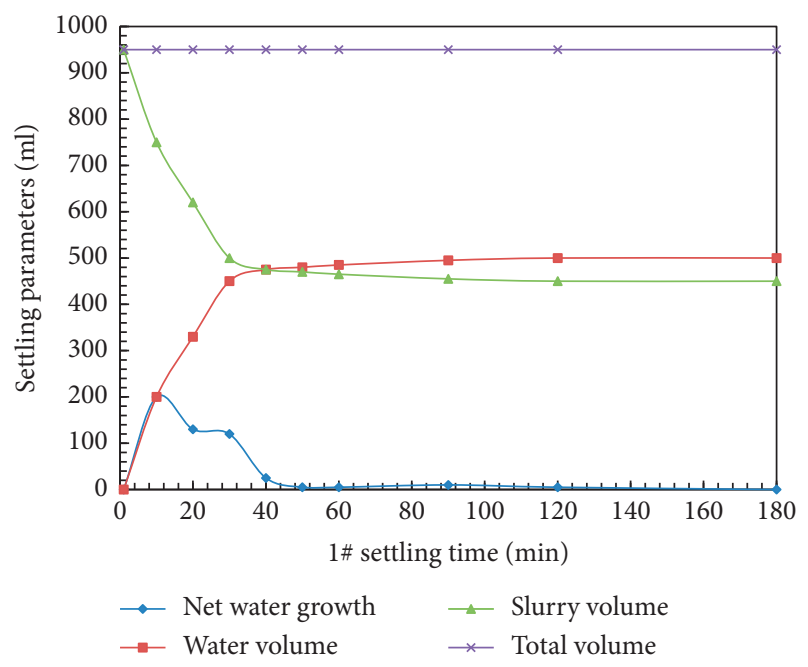

FIgURE 3: Natural sedimentation test parameters of tailings (\#1).

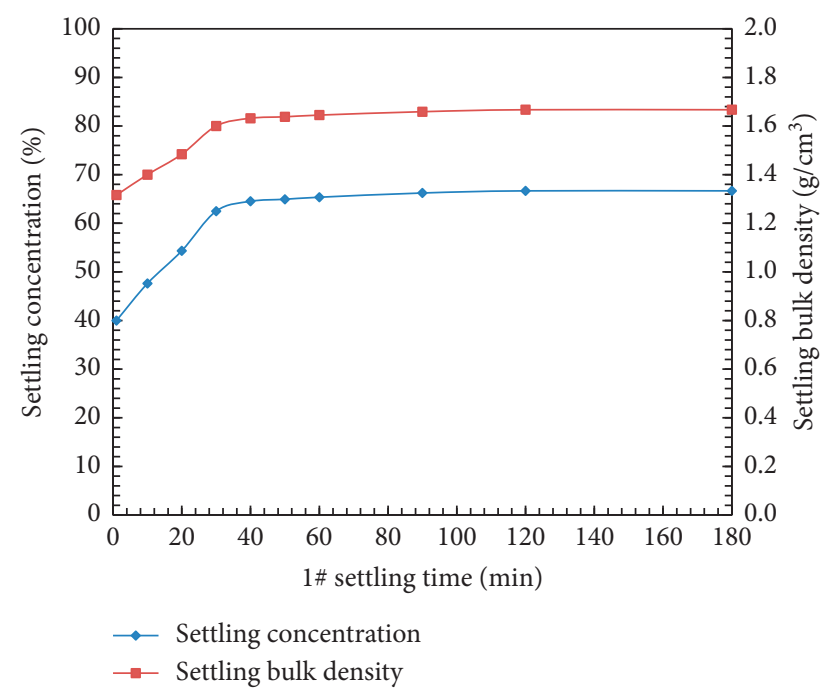

FIGURE 4: Variation curves of natural settling concentration and bulk density (\#1).
$30 \mathrm{~min}$, climbing up slowly from $62.5 \%$ to $66.67 \%$ during the 30-40 min interval, and remaining the same after $120 \mathrm{~min}$.

3.2. Flocculating Sedimentation Using Pheomax9010 BASF. In this experiment, Pheomax9010 BASF at a dosage of $20 \mathrm{~g} / \mathrm{t}$ was used as the flocculant. The concentration of the flocculant solution was $3 \%$, and the initial concentration of the tailing slurry was $40 \%$. Combined with the technological parameters in the future daily filling production process, the concentration of tailing mortar transported from the dressing plant to the filling slurry preparation station is about $40 \%$, so the preparation concentration of the tailing mortar of this group is $40 \%$.

The variations in the flocculating sedimentation test parameters of the tailings with Pheomax9010 BASF are shown in Figure 5. The net water growth increased gradually before reaching the maximum of $370 \mathrm{ml}$ at $10 \mathrm{~min}$, began to decrease after $10 \mathrm{~min}$, and remained the same after $20 \mathrm{~min}$. The water volume increased rapidly within $0-10 \mathrm{~min}$, climbed up slowly during the $10-40 \mathrm{~min}$ interval, and remained the same after $40 \mathrm{~min}$. The slurry volume decreased rapidly within $0-10 \mathrm{~min}$, decreased continuously at a low speed during the 10-40 min interval, and stabilized after $40 \mathrm{~min}$. The total water and slurry volumes followed a linear development law throughout the entire experiment and did not show evident changes.

The variation curves of the settling concentration and bulk density of the tailings with Pheomax9010 BASF are shown in Figure 6 . The settling bulk density increased rapidly and reached $1.517 \mathrm{t} / \mathrm{m}^{3}$ in the first $10 \mathrm{~min}$, increased slowly from $1.517 \mathrm{t} / \mathrm{m}^{3}$ to $1.577 \mathrm{t} / \mathrm{m}^{3}$ only within the 10-40 min interval, and remained the same after $40 \mathrm{~min}$. The settling concentration varied similarly with the settling bulk density, increasing rapidly and reaching $56.82 \%$ in the first $10 \mathrm{~min}$, climbing up slowly from $56.82 \%$ to $60.98 \%$ within the $10-40 \mathrm{~min}$ interval, and stabilizing after $40 \mathrm{~min}$.

3.3. Flocculating Sedimentation Using $M^{3} 42$ BASF. In this experiment, $M^{3} 42$ BASF at a dosage of $20 \mathrm{~g} / \mathrm{t}$ was used as the flocculant. The concentration of the flocculant solution was 


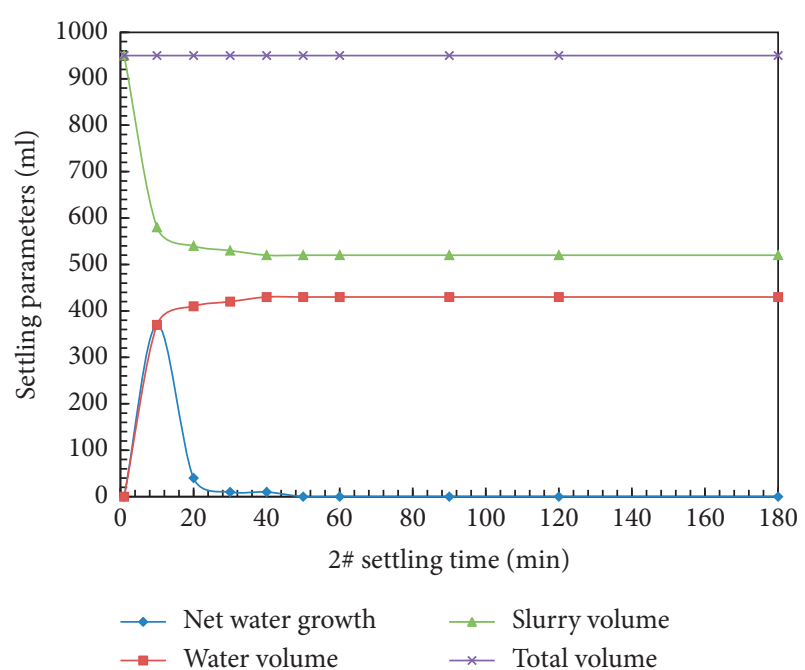

FIGURE 5: Flocculating sedimentation test parameters of tailings (\#2).

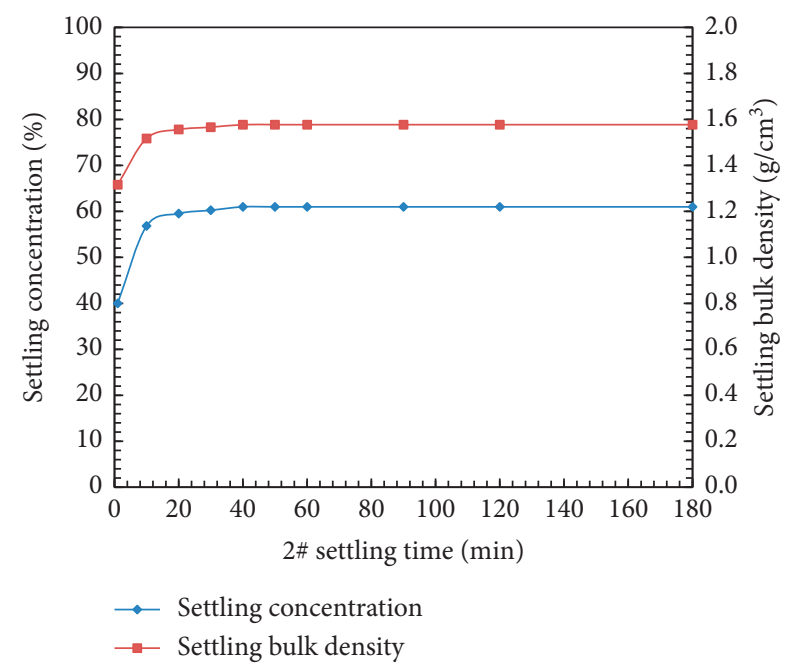

Figure 6: Variation curves of flocculation settling concentration and bulk density (\#2).

$3 \%$, and the initial concentration of the tailing slurry was $40 \%$.

The variations in the flocculating sedimentation test parameters of the tailings with $\mathrm{M}^{3} 42$ BASF are shown in Figure 7 . The net water growth increased gradually before reaching the maximum of $125 \mathrm{ml}$ at $20 \mathrm{~min}$, began to decrease after $20 \mathrm{~min}$, and remained the same after $50 \mathrm{~min}$. The water volume continuously increased rapidly within 0-30 min, climbed up slowly during the 30-180 min interval, and remained the same after $180 \mathrm{~min}$. The slurry volume decreased rapidly within 0-30 min, decreased continuously at a low speed during the $30-180 \mathrm{~min}$ interval, and stabilized after $180 \mathrm{~min}$. The total water and slurry volumes followed a linear development law throughout the entire experiment and did not show evident changes.

The variation curves of the settling concentration and bulk density of the tailings with $\mathrm{M}^{3} 42 \mathrm{BASF}$ are shown in

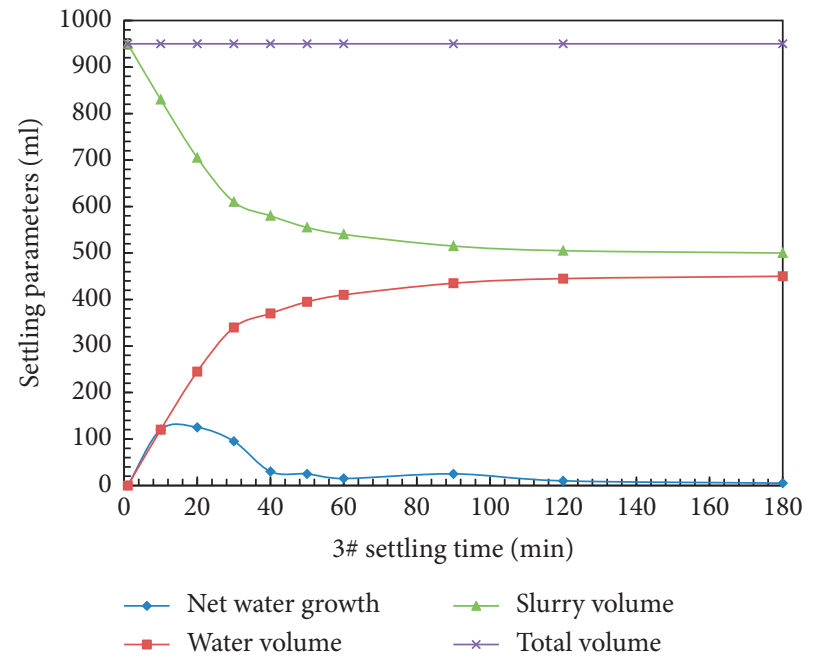

FIGURE 7: Flocculating sedimentation test parameters of tailings (\#3).

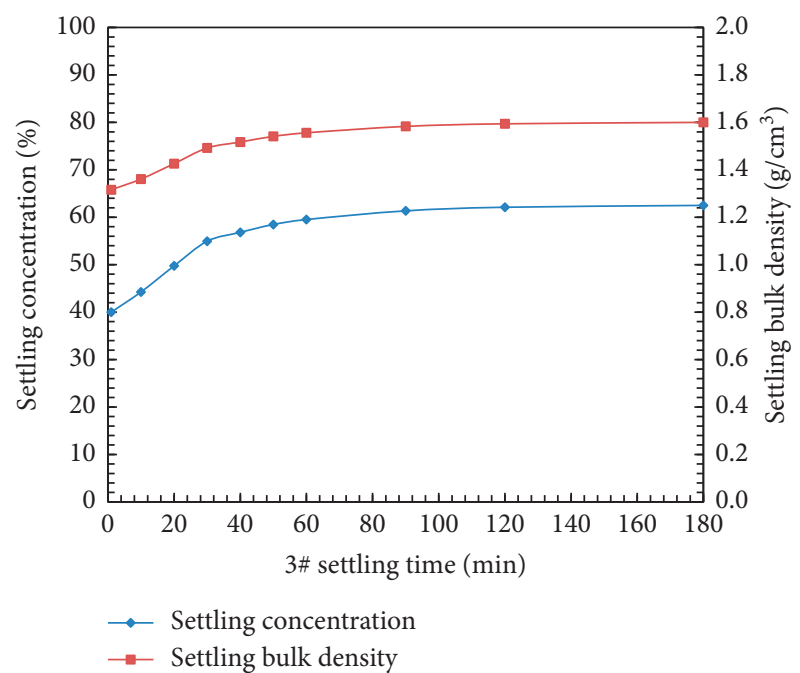

Figure 8: Variation curves of flocculation settling concentration and bulk density (\#3).

Figure 8 . The settling bulk density increased gradually and reached $1.492 \mathrm{t} / \mathrm{m}^{3}$ in the first $30 \mathrm{~min}$, climbed up slowly from $1.492 \mathrm{t} / \mathrm{m}^{3}$ to $1.600 \mathrm{t} / \mathrm{m}^{3}$ within the $30-180 \mathrm{~min}$ period, and remained the same after $180 \mathrm{~min}$. The settling concentration varied similarly with the settling bulk density, increasing gradually and reaching $54.95 \%$ in the first $30 \mathrm{~min}$, climbing up slowly from $54.95 \%$ to $62.5 \%$ within the 30-180 min interval, and stabilizing after $180 \mathrm{~min}$.

\subsection{Flocculating Sedimentation Using Anionic Flocculant with} 12,000,000 MW (Northern Chemistry). In this experiment, the anionic flocculant with 12,000,000 MW (Northern Chemistry) at a dosage of $40 \mathrm{~g} / \mathrm{t}$ was used. The concentration of the flocculant solution was 3\%o, and the initial concentration of the tailing slurry was $40 \%$. 
Figure 9 shows that in the sedimentation experiment with the anionic flocculant with 12,000,000 MW (Northern Chemistry), the net water growth increased gradually before reaching the maximum of $335 \mathrm{ml}$ at $10 \mathrm{~min}$, began to decrease within the 10-40 min interval, and remained the same after $50 \mathrm{~min}$. The water volume increased rapidly within 0-10 min, climbed up slowly during the 10-60 min interval, and remained the same after $60 \mathrm{~min}$. The slurry volume decreased rapidly within $0-10 \mathrm{~min}$, decreased continuously at a low speed during the 10-60 min interval, and stabilized after $60 \mathrm{~min}$. The total water and slurry volumes followed a linear development law throughout the entire experiment and did not show evident changes.

Figure 10 shows that in the sedimentation experiment with the anionic flocculant with 12,000,000 MW (Northern Chemistry), the settling bulk density increased gradually and reached $1.488 \mathrm{t} / \mathrm{m}^{3}$ in the first $10 \mathrm{~min}$, climbed up slowly from $1.488 \mathrm{t} / \mathrm{m}^{3}$ to $1.600 \mathrm{t} / \mathrm{m}^{3}$ within the $10-60 \mathrm{~min}$ interval, and remained the same after $60 \mathrm{~min}$. The settling concentration varied similarly with the settling bulk density, increasing rapidly and reaching $54.64 \%$ in the first $10 \mathrm{~min}$, increasing continuously from $54.64 \%$ to $62.5 \%$ at a low speed within the 10-60 min interval, and stabilizing after $60 \mathrm{~min}$.

3.5. Flocculating Sedimentation Using Nonionic Flocculant with 12,000,000 MW (Northern Chemistry). In this experiment, the nonionic flocculant with $12,000,000 \mathrm{MW}$ (Northern Chemistry) at a dosage of $40 \mathrm{~g} / \mathrm{t}$ was used. The concentration of the flocculant solution was $3 \%$, and the initial concentration of the tailing slurry was $40 \%$.

The variations in the flocculating sedimentation test parameters of the tailings with the nonionic flocculant with 12,000,000 MW (Northern Chemistry) are shown in Figure 11 . The net water growth increased gradually before reaching the maximum of $170 \mathrm{ml}$ at $20 \mathrm{~min}$, began to decrease during the $20-120$ min interval, and remained the same after $120 \mathrm{~min}$. The water volume increased rapidly during the $0-20 \mathrm{~min}$ interval, climbed up slowly during the 20-120 min period, and remained the same after $120 \mathrm{~min}$. The slurry volume decreased continuously within $0-20 \mathrm{~min}$, reached a turning point during the $20-120 \mathrm{~min}$ interval, and stabilized after $120 \mathrm{~min}$. The total water and slurry volumes followed a linear development law throughout the entire experiment and did not show evident changes.

The variation curves of the settling concentration and bulk density of the tailings with the nonionic flocculant with $12,000,000 \mathrm{MW}$ (Northern Chemistry) are shown in Figure 12. The settling bulk density increased gradually and reached $1.531 \mathrm{t} / \mathrm{m}^{3}$ in the first $30 \mathrm{~min}$, climbed up from $1.531 \mathrm{t} / \mathrm{m}^{3}$ to $1.625 \mathrm{t} / \mathrm{m}^{3}$ at a low speed within the 30-120 min interval, and remained the same after $120 \mathrm{~min}$. The settling concentration varied similarly with the settling bulk density, increasing gradually and reaching $57.8 \%$ in the first 30 min, climbing up from $57.8 \%$ to $64.1 \%$ at a low speed within the 30-120 min interval, and stabilizing after $120 \mathrm{~min}$.

3.6. Analysis of Natural and Flocculating Sedimentation Experimental Results. The times for reaching the final settling,

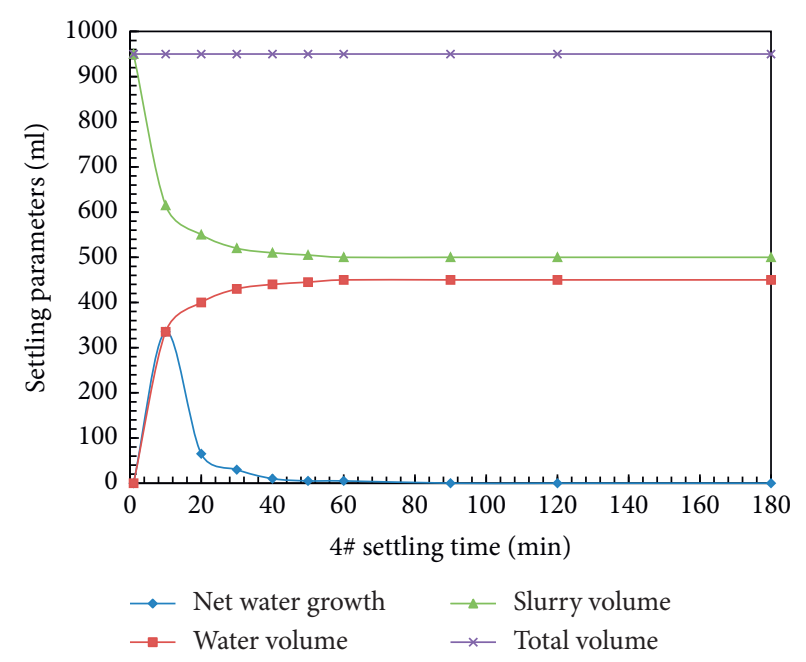

FIGURE 9: Flocculating sedimentation test parameters of tailings (\#4).

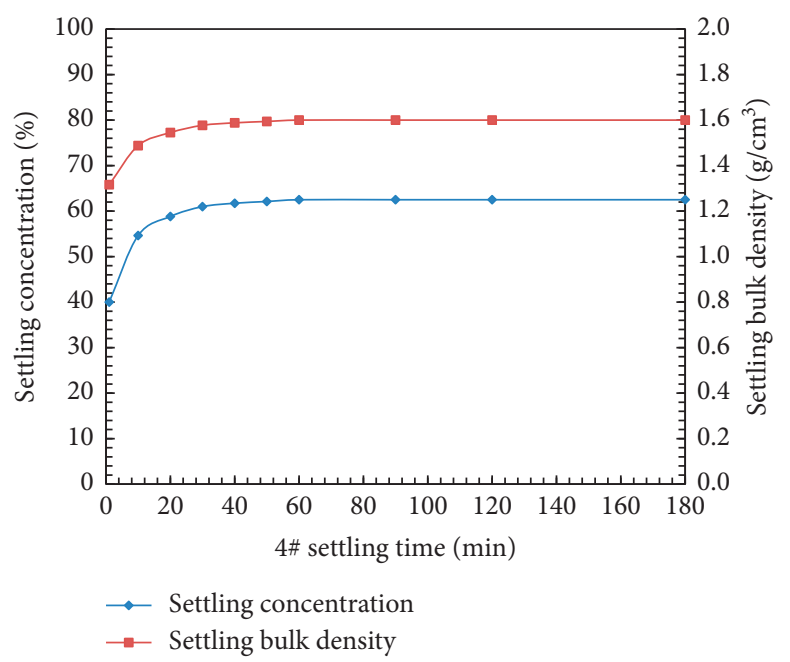

FIGURE 10: Variation curves of flocculation settling concentration and bulk density (\#4).

maximum settling concentration, and maximum settling bulk density of the five experiments were analyzed. The flocculants were ranked on the basis of the required final settling concentration of 55\% (Table 3). To show an intuitive representation of the difference between the natural and flocculating sedimentation of the tailings, data of the natural sedimentation experiment (\#1) and those of the four flocculating sedimentation experiments (\#2-5) at different time periods were summarized and integrated in the same plane coordinates. The settling concentration and bulk density at $30,60,90$, and $120 \mathrm{~min}$, as well as test images at these time periods, are shown in Figures 13-16, respectively. The volume of the cylinders shown in the images is $1000 \mathrm{ml}$. Five cylinders were placed in a line and represented the following (from left to right): natural sedimentation (\#1), flocculating sedimentation using Pheomax9010 BASF (\#2), flocculating sedimentation using $\mathrm{M}^{3} 42$ BASF (\#3), flocculating 


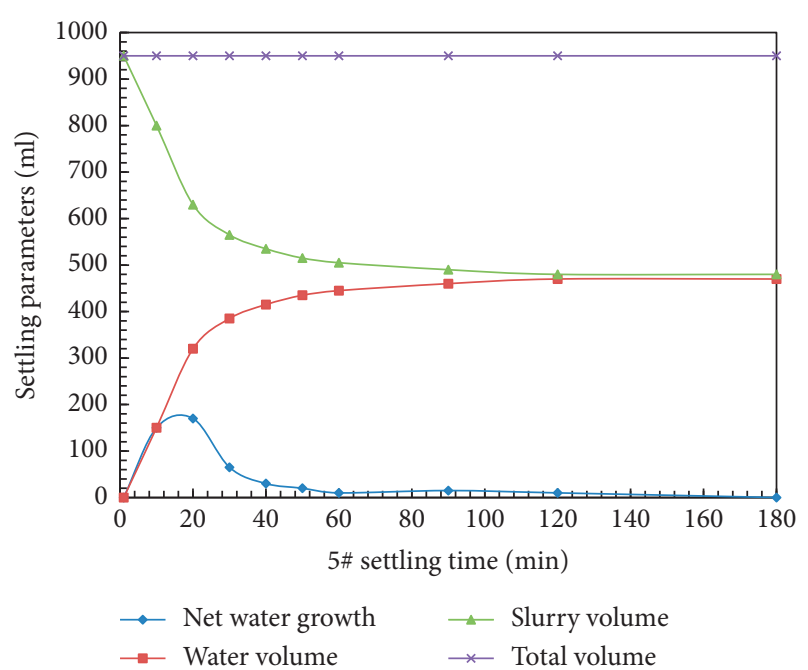

FIgURE 11: Flocculating sedimentation test parameters of tailings (\#5).

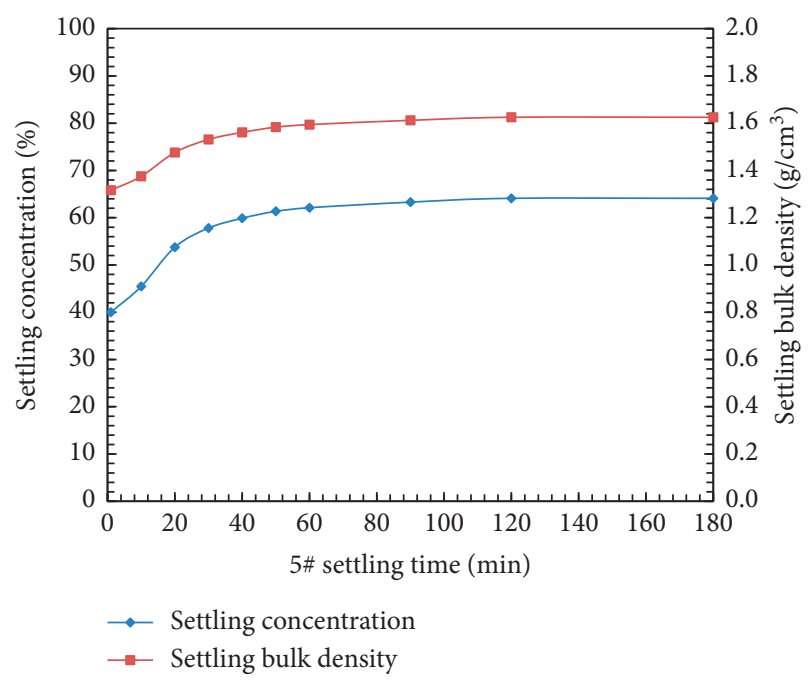

FIGURE 12: Variation curves of flocculation settling concentration and bulk density (\#5).

sedimentation using anionic flocculant with 12,000,000 MW (Northern Chemistry) (\#4), and flocculating sedimentation using nonionic flocculant with 12,000,000 MW (Northern Chemistry) (\#5).

As shown in Table 3 and Figures 13-16, 120 min was needed in test \#1 to reach the maximum settling concentration in Chenchao Iron Mine. The maximum settling concentration was $66.67 \%$, and the maximum bulk density was $1.667 \mathrm{~g} / \mathrm{cm}^{3}$. Meanwhile, only $40 \mathrm{~min}$ was needed in test \#2 to reach the maximum settling concentration of $60.98 \%$, and the maximum bulk density was $1.577 \mathrm{~g} / \mathrm{cm}^{3}$. In test \#3, the maximum settling concentration of $62.5 \%$ was reached at $180 \mathrm{~min}$, and the maximum bulk density was $1.600 \mathrm{~g} / \mathrm{cm}^{3}$. In test \#4, 60 min was needed to reach the maximum settling concentration of $62.5 \%$, and the maximum bulk density was $1.600 \mathrm{~g} / \mathrm{cm}^{3}$. In test $\# 5$, the maximum settling concentration of $64.1 \%$ was reached at $120 \mathrm{~min}$, and the maximum bulk density was $1.625 \mathrm{~g} / \mathrm{cm}^{3}$.

The comparison of the four flocculating sedimentation experimental results shows that different flocculants cause tailings to show different settling characteristics. Pheomax9010 BASF $(20 \mathrm{~g} / \mathrm{t})$ achieved the highest settling speed, followed by the anionic flocculant with $12,000,000 \mathrm{MW}$ (Northern Chemistry) $(40 \mathrm{~g} / \mathrm{t})$, nonionic flocculant with $12,000,000 \mathrm{MW}$ (Northern Chemistry) $\left(40 \mathrm{~g} / \mathrm{t}\right.$ ), and $\mathrm{M}^{3} 42$ BASF $(20 \mathrm{~g} / \mathrm{t})$. The sequence of final settling concentration from large to small is natural sedimentation (66.67\%), nonionic flocculant with $12,000,000$ MW (Northern Chemistry) (64.18\%), anionic flocculant with $12,000,000$ MW (Northern Chemistry) (62.5\%), $\mathrm{M}^{3} 42$ BASF (62.53\%), and Pheomax9010 BASF (61.12\%). The future filling technique only requires a settling concentration of tailings of at least 55\% hence, the flocculant that can reach 55\% settling concentration in the shortest time is the best. The experimental results show that using Pheomax9010 BASF, the settling concentration of the tailing slurry could reach 55\% in $40 \mathrm{~min}$, thus indicating that Pheomax9010 BASF is the optimal flocculant material for tailing settling in Chenchao Iron Mine. The anionic flocculant with 12,000,000 MW (Northern Chemistry), could lead to a 55\% settling concentration in $60 \mathrm{~min}$, is the second best.

In summary, although natural sedimentation took a long time to reach the final settling state, the settling concentration and bulk density in this setting were relatively high and accompanied with tight tailing stacking structures. The supernate was light grey during the settling process, was not clear in the beginning, and became transparent in the final settling state. The natural sedimentation images show that the slurry volume under natural sedimentation was the highest in the beginning but became the lowest in the end, thus resulting in high settling concentration and bulk density. Under natural conditions, $120 \mathrm{~min}$ was needed to reach the final settling state. The final settling concentration was $66.67 \%$, and the final settling bulk density was $1.667 \mathrm{t} / \mathrm{m}^{3}$.

The comparison of the flocculating experiments shows that the tailing slurry has high sedimentation speed. The supernate can become transparent in a short time and was most transparent when Pheomax9010 BASF was used. Furthermore, the final settling state and the best settling performance were achieved in the shortest time when this flocculant was used. The images show that the tailings became relatively fluffy at their final settling. The slurry volumes in all flocculating experiments were higher than that under natural sedimentation, thus resulting in relatively smaller settling concentration and bulk density. Pheomax9010 BASF achieved the smallest settling concentration and bulk density, reaching the final settling state in only $40 \mathrm{~min}$. The final settling concentration was $60.98 \%$, and the final settling bulk density was $1.577 \mathrm{t} / \mathrm{m}^{3}$. These parameters can meet settling requirements. The required $\geq 55 \%$ settling concentration meant that the key to evaluating the performances of the flocculating materials was the time. Therefore, Pheomax9010 BASF is the best flocculant for Chenchao Iron Mine. 
TABLe 3: Statistics on parameters at final settling.

\begin{tabular}{lcccc}
\hline Test no. & $\begin{array}{c}\text { Time for reaching the final settling } \\
(\mathrm{min})\end{array}$ & $\begin{array}{c}\text { Maximum settling concentration } \\
(\%)\end{array}$ & $\begin{array}{c}\text { Maximum settling bulk } \\
\text { density }\left(\mathrm{t} / \mathrm{m}^{3}\right)\end{array}$ & $\begin{array}{c}\text { Order of flocculants } \\
\# 1\end{array}$ \\
\hline 2 & 120 & 66.67 & 1.667 & Standard \\
$\# 3$ & 40 & 60.98 & 1.577 & 1 \\
$\# 4$ & 180 & 62.50 & 1.600 & 3 \\
$\# 5$ & 60 & 62.50 & 1.600 & 2 \\
\hline
\end{tabular}

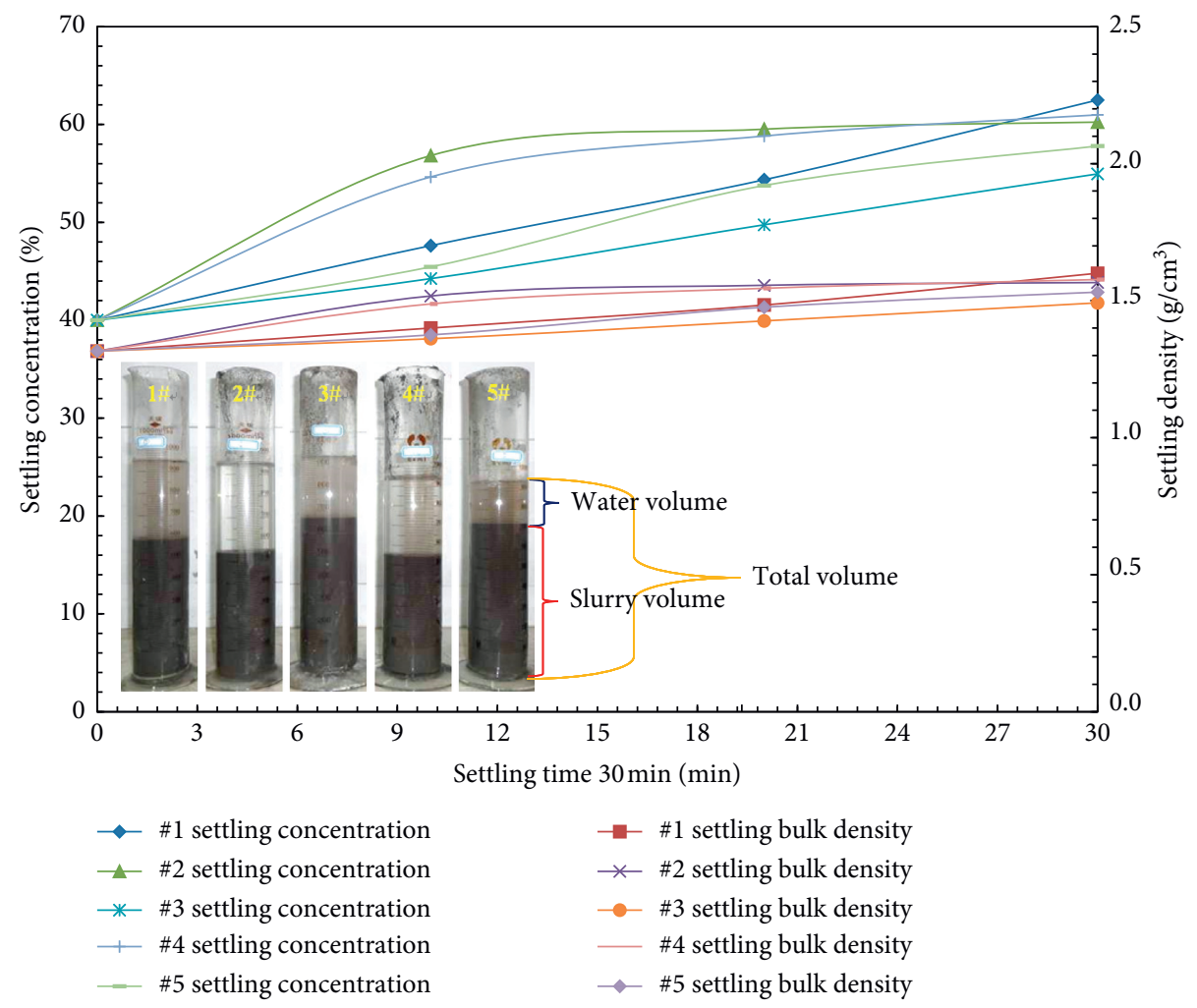

FIGURE 13: Curves of settling concentration and bulk density (30 min).

\section{Discussion}

The settling performance of tailings often influences the tailing filling system considerably. With slow sedimentation of tailings, preparing high-concentration filling slurry and meeting the required physical properties, such as strength of fill, are difficult. The sedimentation of tailings is often influenced by their properties. An appropriate amount of flocculant is often needed for tailings with special properties and slow settling. Jiao et al. determined the best flocculant through flocculating sedimentation experiment of tailings. Consequently, the tailing slurry reached the desired concentration and the prepared strength of fill could meet mining requirements [22, 23]. Wang and $\mathrm{Li}$ et al. achieved high-concentration filling slurry by combining a high-efficiency deep-cone thickener and flocculant. The entire thickening system had stable working conditions and good performance [24, 25].

To provide references for future filling system design and environment-friendly treatment of abundant solid waste, the optimal flocculant was chosen by the current study considering the difficult settling of ultra-fine iron tailings with rich gypsum. Tailing slurry in the future filling system for Chenchao Iron Mine will be prepared with a deep-cone thickener. Hence, related studies that combine properties of tailings shall be conducted. In mines with tailing filling, sedimentation properties of tailings are important in technique connection, working efficiency, and comprehensive effect of enterprises. Filling techniques with tight technique connection, few errors, and high efficiency are important in enterprise development and competition. Therefore, a method that allows for the quickest settling of tailings should be developed to provide technological references for increasing the preparation efficiency of filling slurry.

A large area in the Yangtze River basin in China has ore mines. Solid wastes from mining production are stacked in the surface tailing pond and migrate outside through natural factors, such as wind and rain, thus causing potential risks to surrounding land, rivers, and underground water. Hence, effective measures should be adopted to avoid surrounding environmental pollution by heavy metals and other harmful elements in solid waste. As an ultra-large mine in the Wuhan 


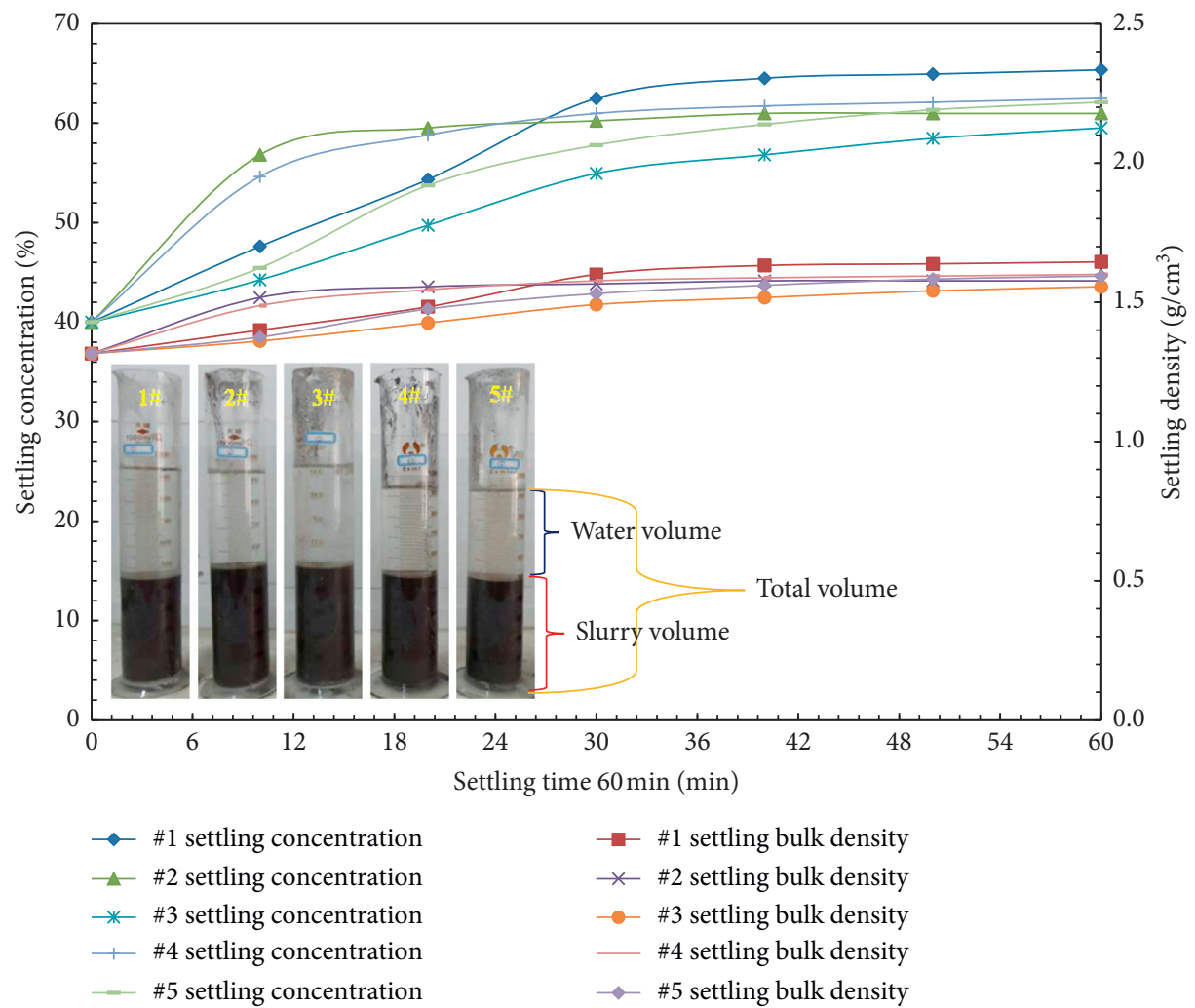

FIGURE 14: Curves of settling concentration and bulk density (60 min).

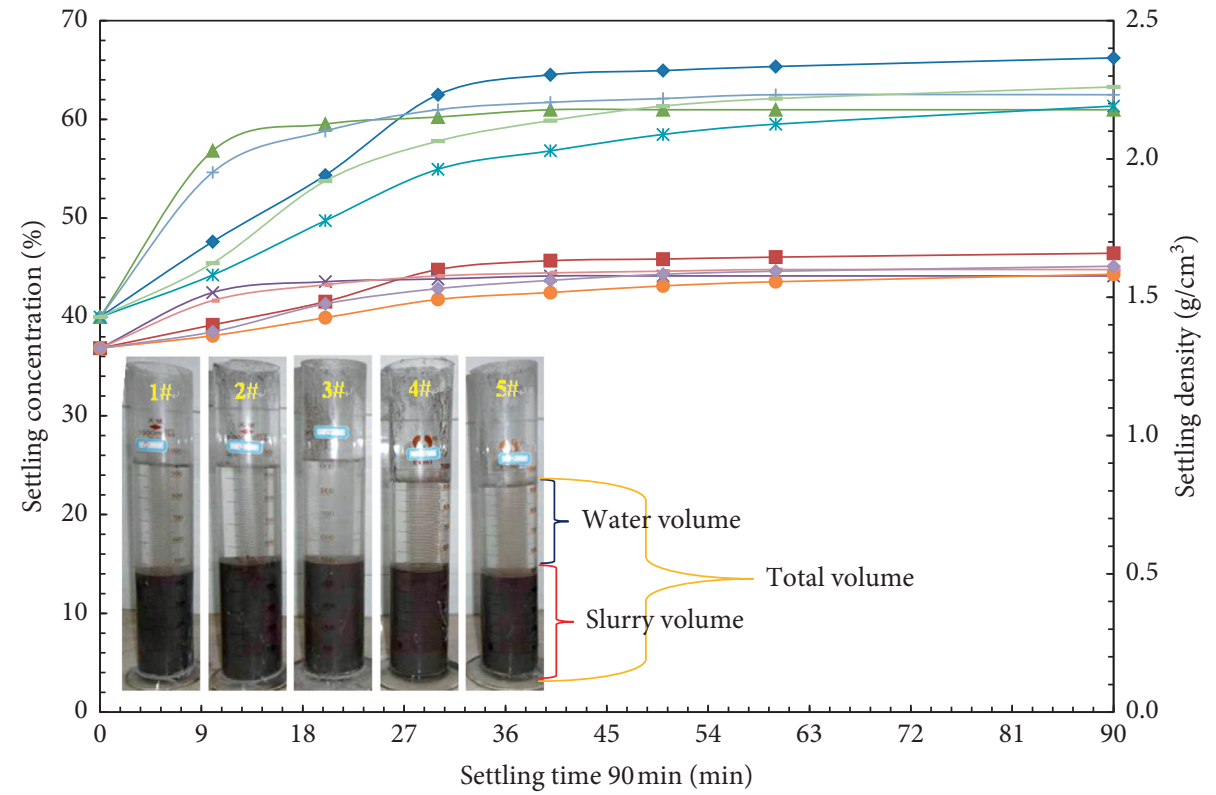

- \#1 settling concentration

-— \#1 settling bulk density

$\triangle \_$\#2 settling concentration

$*$ \#2 settling bulk density

$\rightarrow$ \#3 settling concentration

- $\# 3$ settling bulk density

1 \#4 settling concentration

_ \#4 settling bulk density

- \#5 settling concentration

$\multimap$ \#5 settling bulk density

FIGURE 15: Curves of settling concentration and bulk density (90 min). 


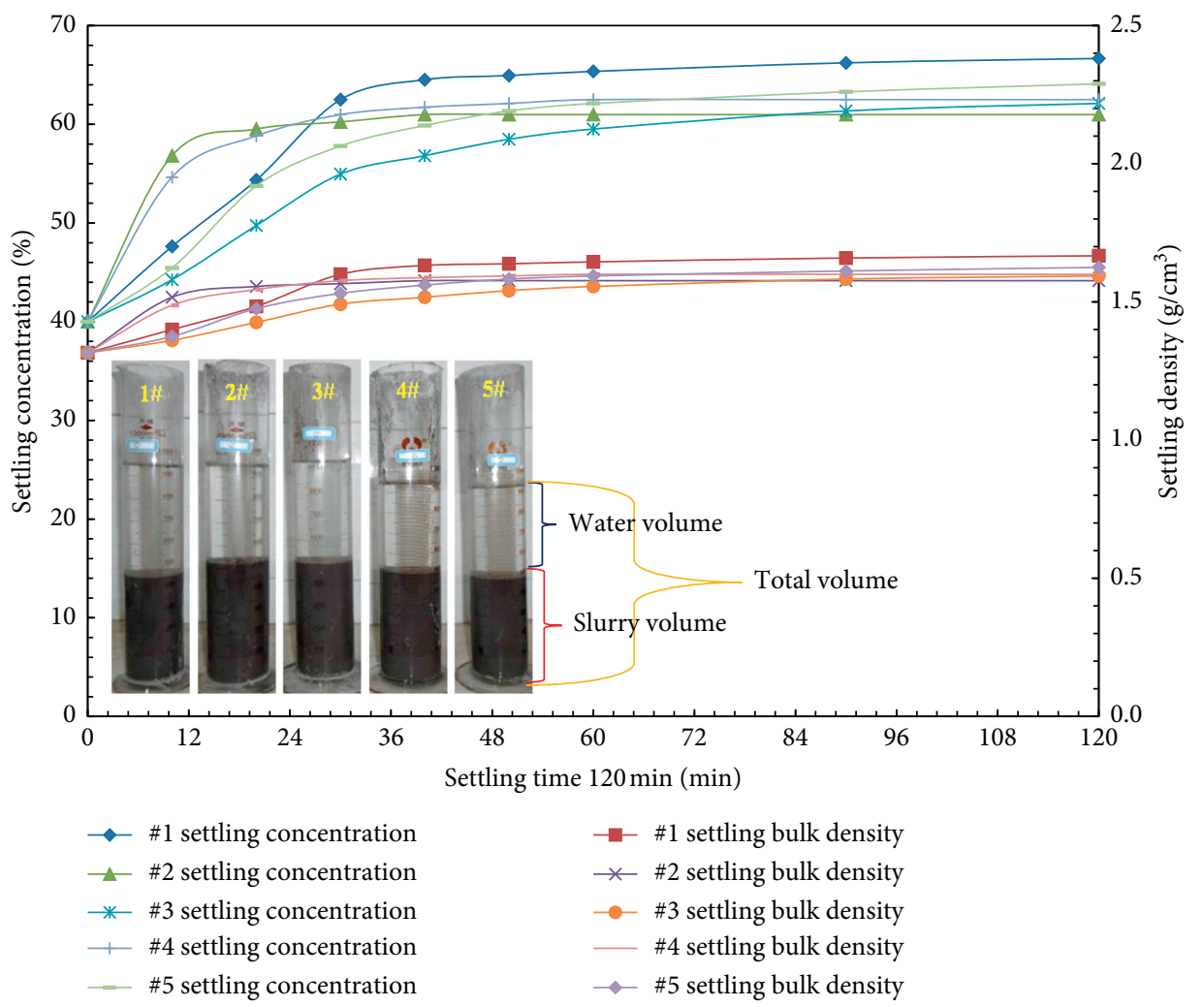

Figure 16: Curves of settling concentration and bulk density (120 min).

economic circle and along the Yangtze River basin, Chenchao Iron Mine has a long exploitation history. The water and land resources in the Yangtze River basin should thus be protected through the proper disposal of solid waste. Meanwhile, goaf filling engineering is used for the reutilization of solid wastes; hence, studying the sedimentation properties of tailings can provide early technological parameters for filling engineering. Consequently, discussing the flocculating sedimentation performances of ultra-fine iron tailings with rich gypsum is important as it aims to protect the ecological environment in the Yangtze River basin.

\section{Conclusions}

(1) In Chenchao Iron Mine, about $2711 \mathrm{~m}^{3}$ goaf volume arises every day. However, the existing conventional flow filling system can only fill $750 \mathrm{~m}^{3}$ and make selective filling to goaf. The tailing dosage is $745 \mathrm{t} / \mathrm{d}$. The dosage of tailings for comprehensive filling exploitation in the future will increase dramatically to $2692 \mathrm{t} / \mathrm{d}$; thereby, it considerably reduces the stacking amount of tailings in the surface tailing pond. The service life of the tailing pond will thus be prolonged, and tailing emission and disposal cost will be reduced dramatically.

(2) Tailings of Chenchao Iron Mine contain some gypsum and a small number of quartz, which have strong sandiness and easily sink. Moreover, the tailings have a low natural settling rate due to the ultra-fine size of particles, which make the final dense settling state difficult to reach in a short time without a flocculant. A contrast analysis between the natural and flocculating sedimentation of tailings was conducted on the basis of the properties of the tailings in Chenchao Iron Mine. The Pheomax9010 BASF was the most effective. Compared to other flocculants, it can decrease 80 mins to achieve the same settling concentration and settling bulk density.

(3) As shown in the flocculating sedimentation images, the supernate of experiment was the clearest at $30 \mathrm{~min}$ and the sedimentation of tailings was the quickest without the suspending particles. Even the ultra-fine particles sedimented with large ones. The settling concentration of the tailings in experiment was not the highest at $40 \mathrm{~min}$ but still meets the concentration limit of 55\%. Therefore, Pheomax 9010 BASF is recommended as the flocculating sedimentation of tailings in the future.

(4) In the future study of tailings materials, they can be classified according to the detailed grading of granular material; the tailings with special particle size distribution are divided to the size of the corresponding category. Combined with the specific use of tailings materials, mesoscopic and microscopic analysis is conducted to investigate the relationship of particle shape and the settling velocity and to obtain the analytical expression of the granular 
material sedimentation process to the analysis of the related laws and prediction.

(5) As the largest iron mine reserve in the mid-southern region of China, it has a long history of exploitation. The long-term caving exploitation has accumulated great goaf space, and surfaces in some regions have collapsed, thus serious risks exist. Chenchao Iron Mine is the main mine for Wuhan Steel Inc. For goaf management and environment-friendly treatment of solid wastes, Chenchao Iron Mine will gradually use filling mining pattern. This study is a preliminary exploration that provides basic parameters for its future filling system design. The results of this study will be used to guide the goaf management and environment-friendly treatment of solid wastes in the Yangtze River basin.

\section{Data Availability}

The data used to support the findings of this study are available from the corresponding author upon request.

\section{Conflicts of Interest}

The authors declare no conflicts of interest concerning the publication of this paper.

\section{Authors' Contributions}

Daiqiang Deng wrote the main text of the manuscript. Guodong Cao collected and analyzed the data. All authors reviewed and commented on the manuscript.

\section{Acknowledgments}

This work was supported by the NSFC projects of China (51764009), the Guizhou Province Science and Technology Support Plan Project (Grant no. [2018]2836), the Provincial Natural Science Foundation of Hunan (2020JJ5538), the Scientific Research Fund of Hunan Province Education Department (20A475 and 19C1736), and the High-Level Talent Gathering Project in Hunan Province (2019RS1059). The authors are grateful for the financial support for this research.

\section{References}

[1] Y.-n. Yuan, L.-y. Chai, Z.-h. Yang, Y.-p. Laio, X.-h. Deng, and S.-j. Zhang, "Application of polymeric aluminum salts in remediation of soil contaminated by $\mathrm{Pb}, \mathrm{Cd}, \mathrm{Cu}$, and $\mathrm{Zn}$," Journal of Central South University, vol. 20, no. 6, pp. 16381644, 2013.

[2] N. N. DengLiao, J. S. Laskowski, and F. Concha, "The use of ultra-flocculation in optimization of the experimental flocculation procedures," Physicochemical Problems of Mineral Processing, vol. 1, no. 47, pp. 5-16, 2011.

[3] F. H. Wang and D. B. Chen, "Study and application of the technology of slime pulp flocculation and thickening in a vertical sand bin," Metal Mine, vol. 283, no. 1, pp. 21-24, 2000.

[4] X. z. Shi, H. y. Hu, X. h. Du, M. L. Ling, and H. Y. Wang, "Experimental study on flocculating sedimentation of tailings slurry in a vertical sand tank," Mining and Metallurgical Engineering, vol. 30, no. 3, pp. 1-3, 2010.

[5] X. m. Wang, J. x. Liu, Q. s. Chen, C. c. Xiao, and X. h. Wan, "Optimal flocculating sedimentation parameters of unclassified tailings," ScienceљTechnology Review, vol. 32, no. 17, pp. 23-28, 2014.

[6] Z.-n. Li, L.-j. Guo, W.-y. Xu, and C. x. Shi, "Experimental study on flocculation sedimentation of fine tailings," China Mining Magazine, vol. 23, no. S2, pp. 215-218, 2014.

[7] H. Wang, J. Yang, Q. An, and C. b. Han, "Expeirimental study on sedimentation of ultra-fine unclassified tailings," Mining Engineering, vol. 9, no. 5, pp. 27-29, 2011.

[8] X. 1. Zhou and W. b. Zhang, "Methods for settlement experiment of slurry in the measuring cylinder," Nonferrous Metals Mieral Processing Section, vol. 5, pp. 30-32, 2005.

[9] J. j. Wang, W. y. Xu, and L. j. Guo, "Study on flocculation sedimentation rules of full tailings," China Mining Magazine, vol. 21, no. 6, pp. 92-94, 2012.

[10] H. z. Jiao, H. j. Wang, A. x. Wang, X. w. Ji, Q. w. Yan, and $\mathrm{X}$. Li, "Rule and mechanism of flocculation sedimentation of unclassified tailings," Journal of University of Science and Technology Beijing, vol. 32, no. 6, pp. 702-707, 2010.

[11] Q. l. Zhang, Q. s. Chen, X. m. Wang, and C. c. Xiao, "Study on GA-SVM optimal prediction model on flocculating sedimentation parameter of unclassified tailings," Journal of Safety Science and Technology, vol. 10, no. 5, pp. 24-30, 2014.

[12] K. K. Das and P. Somasundaran, "A kinetic investigation of the flocculation of alumina with polyacrylic acid," Journal of Colloid and Interface Science, vol. 271, no. 1, pp. 102-109, 2004.

[13] H. Jiao, A. Wu, H. Wang, S. Zhong, R. Ruan, and S. Yin, “The solids concentration distribution in the deep cone thickener: a pilot scale test," Korean Journal of Chemical Engineering, vol. 30, no. 2, pp. 262-268, 2013.

[14] D. Tao and B. K. Parekh, "Pilot-Scale demonstration of deep cone paste thickening process for phosphatic clay/sand disposal," Separation Science and Technology, vol. 45, no. 10, pp. 1418-1425, 2010.

[15] P. D. ZhangZhao, S. A. Rothenberg, I. H. Heitner et al., "Development of new Bayer process flocculants," Essential Readings in Light Metals: Alumina and Bauxite, vol. 1, pp. 431-435, 1991.

[16] L. Botha and J. B. P. Soares, "The influence of tailings composition on flocculation," The Canadian Journal of Chemical Engineering, vol. 93, no. 9, pp. 1514-1523, 2015.

[17] C. Shi, L. Guo, and C. Yang, "Application of high-efficient thickener size estimation method in copper tailings thickening," Nonferrous Metals Engineering, vol. 7, no. 5, pp. 86-91, 2017.

[18] C. Qi and A. Fourie, "Cemented paste backfill for mineral tailings management: review and future perspectives," Minerals Engineering, vol. 144, no. C, Article ID 106025, 2019.

[19] C. Yang, L. Guo, G. Hou, and Z. Li, "Determination method of the best discharge concentration for fine tailing paste," Metal Mine, vol. 491, no. 5, pp. 29-32, 2017.

[20] A. Wu, Z. Ruan, J. Wang, S. Ying, and C. Ai, "Optimizing the flocculation behavior of ultrafine tailings by ultra-flocculation," Chinese Journal of Engineering, vol. 41, no. 8, pp. 981-986, 2019.

[21] H.-y. Cheng, S.-c. Wu, X.-q. Zhang, and A.-x. Wu, "Effect of particle gradation characteristics on yield stress of cemented paste backfill," International Journal of Minerals, Metallurgy and Materials, vol. 27, no. 1, pp. 10-17, 2020. 
[22] H. z. Jiao, A. x. Wu, H. j. Wang, X. h. Liu, S. k. Yang, and Y. t. Xiao, "Experiment study on the flocculation settlement characteristic of unclassified tailings," Journal of University of Science and Technology Beijing, vol. 33, no. 12, pp. 1437-1441, 2011.

[23] H.-j. Wang, Q.-r. Cheng, A.-x. Wu, Y.-g. Zhai, and X.-p. Zhang, "Study on the thickening properties of unclassified tailings and its application to thickener design," Journal of University of Science and Technology Beijing, vol. 33, no. 6, pp. 676-681, 2011.

[24] Y. Wang, A.-x. Wu, H.-j. Wang, S.-z. Liu, and B. Zhou, "Influence mechanism of flocculant dosage on tailings thickening," Journal of University of Science and Technology Beijing, vol. 35, no. 11, pp. 1419-1423, 2013.

[25] H. Li, H.-j. Wang, A.-x. Wu, H.-z. Jiao, and X.-h. Liu, "Pressure rake analysis of deep cone thickeners based on tailings'settlement and rheological characteristics," Journal of University of Science and Technology Beijing, vol. 35, no. 12, pp. 1553-1558, 2013. 